\title{
Inhaltsverzeichnis
}

\section{Die Anfänge}

1. Palästina und das Römerreich $\ldots \ldots \ldots \ldots \ldots \ldots$

Die römische Eroberung 1. Die hellenistische Zeit 2. Die [3]

Hasmonäer 3. Antipater 4. Herodes der Große 4. Die

Söhne des Herodes 6. Die Prokuratoren 8.

2. Das palästinensische Judentum .......... 10

Die Religion als bindende Kraft 10. Daniel und die [12]

Weltgeschichte 11. Das Reich Gottes 11. Die Messias-

hoffnung in den Psalmen Salomos 12. Die Frömmigkeit 16.

Chasidim und Pharisäer 17. Sadduzäer 19. Amhaarez 21.

Essener 22. Henochbücher 24. Die Stillen im Lande 26.

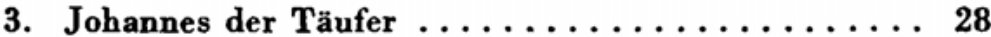

Die Volksüberlieferung 28. Taufe und Buße 30. Fasten [30] und Beten 32. Der Tod des Johannes 32. Die Johannesjünger 32 .

4. Jesus ......................

Die Quellen 34. Methoden der Forschung 36. Die Anfänge [36]

38. Forderung der vollen Hingabe 39. Wunder 39. Das

Reich Gottes 41. Gottes Gerechtigkeit 43. Zöllner und Sünder 43. Der Messias 45. Der Todesweg 47. Sturm in Jerusalem 48. Die Passion 49.

5. Die Urgemeinde . . . . . . . . . . . . .

Die Auferstehung Jesu 52. Entstehung der Urgemeinde in Jerusalem 53. Die "Armen" und "Heiligen" 54. Ihr Judentum 54. Brotbrechen 55. Taufe 55. Vaterunser 56. Fasten und Sabbath 57. Jakobus der Gerechte 58. Alteste und Apostel 58. Sonntagsfeier 60. Neuordnung der Woche 61. Die Hellenisten 62. Stephanus 63. Die erste Verfolgung 63. Anfänge der Mission 64. Die Ürgemeinde in Jerusalem als Zentrale 65.

6. Die jüdische Diaspora .............. 68

Dürftigkeit der Quellen 68. Ausbreitung der Juden 69. [70]

Die Diaspora als Einheit 70. Rechtsstellung der Diasporajuden 71. Ihre Berufe 73. Missionsbestrebungen 74. Propagandaliteratur 75. Proselyten 77. Antisemitismus 78. 
Tumulte in Alexandria unter Caligula und Claudius 79. Seite Syrien 81. Der Geist des Diasporajudentums: die griechische Sprache 82. Die Septuaginta 84. Griechisch als Kultsprache 85. Die alexandrinische Exegetenschule 86. Philo 88. Der Aristeasbrief 94. Die Weisheit Salomos 95. Das vierte und dritte Makkabäerbuch 97. Gebete der griechischen Synagoge 98.

7. Paulus ......................... . 102

Elternhaus und Jugend 102. Der Christenverfolger 103.[104]

Die Bekehrung 103. Damaskus und Jerusalem 104. Erste Missionswirksamkeit 104. Das Problem des Ritualgesetzes 105. Der Apostelkonvent 106. Der Konflikt in Antiochia 106. Das Aposteldekret 107. Kampf gegen die Judaisten 108. Zweite und dritte Missionsreise 109. Verhaftung und Prozeß 110. Seine Krankheit 111. Predigt und Briefe 112. Gotteslehre 113. Gottes Gerechtigkeit 114. Prädestination 116. Erlösung durch Christus 116. Glaube 118. Fleisch und Geist. Christusgemeinschaft 118. Taufe und Sündlosigkeit 120. Das Leben im Geist als Aufgabe 122. Abendmahl 124. Enthusiasmus 125. Der zweite Adam 127. Gesetz und Judentum 127.

8. Die christlichen Missionsgemeinden . . . . . . 132

Die ältesten Missionsgemeinden 132. Rom 133. Xgypten [134]

134. Stände in den Gemeinden 135. Sklavenfrage 136. Eheprobleme 136. Strafrecht 139. Privatrecht 140. Das Opferfleisch 140. Sakramentsmystik 142. Verfassung: charismatische Amter 145. Episkopen und Diakonen 147. Die Frauen 149. Gottesdienstordnung 150. Gegensätze in der Gemeinde 154.

9. Das römische Weltreich und sein religiöses Leben .. 158

Der lateinische Genius 158. Religiöse Restauration des [160] Augustus 159. Religiöses Leben im Osten 160. Das westliche Kleinasien 161. Artemis von Ephesus 162. Mysterien 164. Sabazios 165. Isis und Sarapis 167. Der Herrscherkult 168. Die Göttin Roma 170. Kaiserkult 171. Mysterienreligionen 174. Moralische Elemente 178. Epiktet 178. Poseidonios 180. Die Schrift "von der Welt" 182.

10. Der Ausgang des Judenchristentums . . . . . . 184

Verfolgungen in Jerusalem 185. Der jüdische Krieg 186.[186]

Barkochba 189. Die Christen in Pella 189. Die Judenchristen als Ketzer 191. Nachrichten des 4. Jahrhunderts 192. Der Prophet Elxai 194. Reste in Cypern 197.

11. Die nachapostolische Zeit . . . . . . . . . . . 200

Die neronische Verfolgung 200. Unruhen in Korinth 201. [202]

Der erste Clemensbrief: 202. Amterlehre 203. Das Alte

Testament 204. Paulus 207. Liturgie 209. Das Christen- 
tum der römischen Gemeinde 209. Der zweite Clemensbrief 211. Der Jakobusbrief 212. Die Didache 213. Paulinisches Christentum: der Hebräerbrief 216. Der erste Petrusbrief 223. Der Epheserbrief 226. Die Pastoralbriefe 227. Der Barnabasbrief 229.

12. Johannes . . . . . . . . . . . . . 235

Das johanneische Korpus 235. Das Evangelium: Einheit- [237] lichkeit? 236. Wunder 237. Christus als Logos 237. Zeit- und Ortsangaben 239. Mißverständnisse als Kunstmittel 240. Johannesjünger. Die Juden 241. Geburt von oben 242. Glaube und Liebe 243. Wahrheit, Licht und Leben 244. Parusie. Der Paraklet 245. Gericht und Auferstehung 246. Der Zebedaïde und der ephesinische Johannes 247. Das religionsgeschichtliche Problem 248.

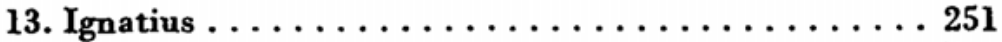

Die Briefsammlung 251. Martyrium des Ignatius 252. Got-[253] tesdienst und Abendmahl 253. Unsterblichkeit und Sehnsucht nach dem Märtyrertode 254. Glaube und Liebe 256. Die Christologie 257. Vater und Sohn 258. Erlösungstheologie 259. Der Mythos vom Stern 260. Gnostische Gegner 262. Klerus und monarchischer Episkopat 264.

14. Marcion . . . . . . . . . . . . . . . . . . 265

Die Allegorisierung des Alten Testaments 265. Marcions [267] Lebensgang 265. Quellen seiner Lehre 266. Gegensatz zum Alten Testament 267. Der gerechte Gott 268. Jesus und das Gesetz 268. Die zwei Götter 269. Paulus als Autorität 270. Die Verfälschung der Uberlieferung durch die Judaisten 270. Marcions Bearbeitung des Evangeliums 271 und der Paulusbriefe 272. Der neue Kanon 273. Die "Antithesen": Der fremde Gott und der Weltschöpfer 274. Christus 275. Höllenfahrt 276. Ethik 277. Ausbreitung der Marcionitenkirche 278. Schüler des Marcion 279. Apelles 279.

15. Die Gnosis . . . . . . . . . . . . . . . . . 282

Ein persischer Mythos bei Dio Chrysostomus 282. Syn- [284] kretismus 284. Plutarch 284. Die Leidener Kosmogonie 285. Die Naassenerpredigt 289. Justin's Baruchbuch 291. Gnosis und Christentum 296. Christliche Systeme: Basilides 300. Isidor 303. Valentinus 309. Herakleon 314. Ptolemäus 315. Der Gott der Gnosis 316. 


\section{Ecclesia catholica}

1. Das römische Weltreich im zweiten und dritten Jahr-

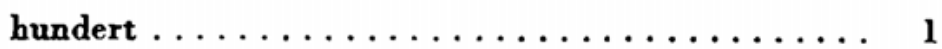

Grenzpolitik im ersten Jahrhundert 1. Trajans Feldzüge 2. [323] Hadrian 3. Mark Aurel 4. Kriege mit dem Sassanidenreich 6. Der wirtschaftliche Niedergang 7. Das Soldatenregiment 9. Literatur unter Trajan 11. Die zweite Sophistik 13. Aristides 14. Lukian 15. Mark Aurel 16. Religiosität bei Aristides und Plutarch 17. Philostrat 17. Heroen- und Gespensterglaube 18. Orientalische Religionen in Rom 20. Syrische Götter 22. Pantheos 23. Ostia 24. Timgad 26. Dougga 27. Rheinische Kulte 29. Mysterienkulte 30 . Das Judentum 33.

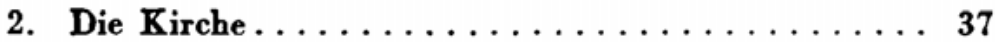

Weltgeschichte bei den Griechen 37 und Juden 39. Christ- [359] liche Apokalyptik 40. Die Ekklesia als Ziel der Weltgeschichte 40. Die Kirche als überirdisches Wesen 42. Die "Propheten" 44. Neue Offenbarungen 46. Die Amter der Episkopen und Diakonen 47. Der Bischof 48. Bischof und Presbyter 50. Bischofslisten: Rom 51. Antiochia und Jorusalem 53. Alexandria 54. Bischöfliche Mutter- und Tochterstädte 55. Synoden 58.

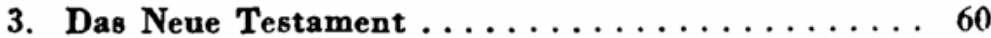

Spruchtradition der Herrenworte 60. Synoptische Evan- [382] gelien 61. Agrapha 62. Apokryphe Sprüche und Evangelien 64. Kindheitsevangelien 65 . Marienlegenden 66 . Pilatusakten 67. Veronika 67. Abgar 68. Die Apostelgeschichte 68. Apokryphe Apostelgeschichten 70. Petrusakten 71. Paulusakten 73. Johannesakten 75. Andreasakten 77. Thomasakten 77. Asketische Stimmung 79. Das Christusbild 80. Gnosis in der Kirche 80. Christliche Apokalyptik 81. Die Offenbarung des Johannes 82. Der Hirte des Hermas 84. Die Petrusakopalypse 85. Die Epistula Apostolorum 86. Die Briefliteratur: Paulus 87. Sammlung der Paulusbriefe 88 . Katholische Briefe 89. Die apostolische Autorität 90. Der Kanon der apostolischen 
Evangelien 91. Ausscheidung der apokryphen Evangelien 92. Das Diatessaron Tatians 93. Pauluskanon des Marcion 94. Der Kanon der katholischen Briefe 95. Apostelgeschichte 96. Kanon der Apokalypsen 97.

4. Glaubensregel und Theologie $\ldots \ldots \ldots \ldots \ldots \ldots 100$

Bekenntnis und Akklamation 100. Das älteste Christus-[422] bekenntnis 101. Grundformen und Erweiterungen 102. Zweigliedriges Bekenntnis 104. Dreigliedriges Bekenntnis 105. Bekenntnis in Rom 106 und im Orient 107. Ausbau des zweiten Artikels 108. Der dritte Artikel 109. Bekenntnisformel und Lehre 110. Gott der Vater 111. Gottes Sohn 112. Die Geburt aus der Jungfrau 113. Adoptianismus 115. Pneumatische Christologie 116. Der heilige Geist 118 und die Kirche 119.

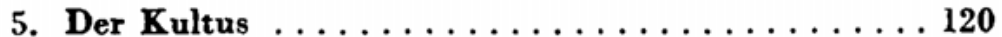

Liturgie der Didache 120. Agapen 121. Sonntagsfeier bei [442] Justin 122. Hippolyts Liturgie 123. Die Eucharistie als Opfer 125. Die Taufe 126. Exorzismus 127. Erweiterungen des Rituals 128. Wochenfssttage 129. Passahfeier 129. Quartodezimaner 130. Osterfeier am Sonntag 131. Osterstreit unter Victor von Rom 131. Pfingsten 132. Totenkult 133. Märtyrerkult 134. Katakomben 135. Die Anfänge der christlichen Kunst 137. Symbolische Figuren 138. Jüdische Bilder 140. Neutestamentliche Darstellungen 141. Die Basilica von Porta Maggiore in Rom 144. Die Aureliergruft in Rom 144.

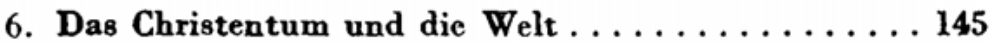

Die Mission und ihre Ansatzpunkte 145. Anmeldung zum [467] Katechumenat 148. Verbotene Berufe 149. Christliche Lebenshaltung 150. Die Christen als "Feinde der Menschheit" 152. Plinius und Trajan über Christenprozesse 154. Staatliche Grundsätze 155 und Gesetze 156. Erste Verfolgungen 158. Lyon und Vienne 159. Der Märtyrer als Enthusiast 160. Perpetua 161. Märtyrerakte in Protokollform 162. Die syrische Dynastie 163. Neue Verfolgungen im 3. Jahrhundert 164 . Verfolgung des Decius 164. Gallus und Valerian 169. Toleranzedikt des Gallienus 171.

7. Die Apologeten . . . . . . . . . . . . . 172

Kritik am Christentum 172. Celsus 172. Die ersten Apo- [494] logeten: Quadratus 175. Aristides 176. Justin 178. Dämonenlehre 179. Weissagungsbeweis 179. Logoslehre 180. Christentum als wahre Philosophie 182. Ethik 184. Gemeindelehren.184. Tatian 186. Athenagoras 187. Theophilos. Brief an Diognet. Minucius Felix 188. 
8. Kleinasien und der Montanismus . . . . . . . 190

Ausbreitung des Christentums in Kleinasien 190. Oster- [512] streit 191. "Dynamistische“ und "monarchianische“" Theologie 191. Praxeas 191. Sakramentstheologie 193. Inschrift des Aberkios 193. Die "neue Prophetie" 195. Montanus 196. Eschatologische Stimmung 197. Asketische Forderungen: Ehelosigkeit. Fasten 199. Opfergaben 200. Spätere Formen 201. Martyriumssehnsucht 201. Ablehnung von seiten der Kirche 202. Versöhnungsversuche 203.

9. Gallien . . . . . . . . . . . . . . . . . . . 206

Beziehungen zu Kleinasien 206. Irenaeus 208. Sein „Elen-[528] chos" 208. Abwehr der Spekulation 210. Kanon und Glaubensregel 211. Die bischöfliche Tradition 211. Gott und sein Logos 212. Erlösung durch „Rekapitulation“" 213. Sakramentslehre 214. Die kirchliche Frömmigkeit als Grundlage der Theologie 216.

10. Afrika . . . . . . . . . . . . . . . . . 219

Berber, Punier, Römer 219. Lateinische Literatur 219. La-[541] teinische Bibel 220. Ausbreitung des Christentums 221. Märtyrer von Scilli 221. Tertullian 222: sein Stil 223. Gelehrsamkeit 223. Temperament 224. Apologetik 225. Ethik; der Montanismus 225. Kampf gegen die Kirche 226. Seine Grunderkenntnis 227. Unspekulative Theologie 227. Glückliche Formulierungen 228. Sein Ausgang 228. Cyprian 229. Die Verfolgung des Decius 230. Einigung mit Rom über die Frage der Gefallenen 231. Opposition der Konfessoren und Presbyter 232. Novatus und Felicissimus 233. Cyprians Schriften de lapsis und de unitate ecclesiae 234. Die Synode vom Mai 251: 235. Schisma des Fortunatus in Carthago, des Novatian in Rom 236. Cyprian und Cornelius 236. Cyprian und Stephan von Rom 238. Der Ketzertaufstreit 239. Tod des Stephan 241 und des Cyprian 242.

il. Rom

Blüte der Stadt 244. Einheit der Gemeinde 245. Gnostiker [566] in Rom. Osterfragen 246. Viktor und der Osterstreit 247. Die "Kleinasiatische Frage" 248. Theologische Bewegungen 248. Monarchianismus. Sabellius 249. Kallist und Hippolyt 250. Hippolyt als Schriftsteller 251. Das Bußedikt des Kallist 253. Ausgang des Hippolyt und des Pontian 254. Fabian 254. Neuordnung des Klerus. Die „Ordines minores“ 255 . Die Verfolgungszeit 257 . Novatian und Cornelius 258. Verbreitung der Novatianer 259. Die Grundsätze des Stephanus und die Theorie des Cyprian 261. Dionysius von Rom 263. 
12. Syrien und sein Hinterland

Antiochia als christliches Zentrum 264. Tritt erst seit 250 [586] hervor 266. In Syrien entsteht ein nationales Christentum: Edessa 266. Bardesanes 267. Seine Lehre 267. Palut erster Bischof von Edessa 271. Harmonios 271. Christentum in der Osroëne. Tatians Einfluß 272. Arbela. Syrisches Christentum bei Afrahat 273. Ausbreitung am östlichen Tigrisufer 274. Krisis im Judentum 275. Mani 276. Seine Lehre 277. Der Mythus 279. Ausklang 282.

13. Agypten

Gnostisches Christentum der Frühzeit 283. Bischof Deme-[605] trius 284. Pantainos und die Katechetenschule 284. Klemens Alexandrinus 285. Schriften 286. Stil 287. Der Protreptikos 288. Der Paidagogos 291. Vom Reichtum 295. Die Stromateis 297. Origenes 305. Der mittlere Platonismus 308. Schriften des Origenes 311. Die Hexapla 313. Sein System 317. Origenes als Bibelforscher 325 . 
XXXII

\section{Die Reichskirche bis zum Tode Julians}

1. Zusammenbruch und Neubau des Reiches ......... 1 Angriffe der Germanen und der Perser 1. Rheinisches Reich [655] des Postumus 2. Das palmyrenische Reich 3. Claudius der Gotensieger und Aurelian 3. Neuer Sonnenkult 4. Diokletian 5. Die Tetrarchie 6. Hofzeremoniell 9. Neugliederung des Reiches 9. Steuerreform 10. Münzwesen 11. Preistarif 11. Heeresreform 12. Bauten 13. Bildende Kunst 15. Literatur 17. Plotin 17. Porphyrius 24. Seine Askese 27. Schrift gegen die Christen 28. Chaldäische Orakel und Theurgie 32. Hermetische Schriften 33. Jüdischer Einfluß 37. Zauberpapyri 38.

2. Der Endkampf des Christentums . . . . . . . . . 42

Wachsende Ausbreitung des Christentums 42. Kirchen- [696] bauten 43 . Vereinzelte Konflikte 44. Edikt des Diokletian 45: seine Vorgeschichte 45. Galerius 46. Edikte gegen Verwandtenehen und Manichäer mit altrömischer Motivierung 47. Palastbrand und Unruhen. Zweites und drittes Edikt. 49. Blutige Verfolgung 50. Viertes Edikt 52. Abdankung des Diokletian und Maximian 53. Erhebung des Konstantin und des Maxentius 53. Die zweite Tetrarchie 54. Verfolgung unter Maximin 55. Toleranzedikt und Tod des Galerius 57. Weitere Verfolgung durch Maximin 58. Konstantin gegen Maxentius 59. Schlacht am Ponte Molle 60. Legenden 60 . Mailänder Toleranzbeschlüsse 62. Licinius' Sieg auf dem Campus Serenus 63. Maximins Tod 64. Des Licinius Rache. Diokletians Tod 64. Licinius gegen die Christen 65. Sein Sturz. Konstantin Alleinherrscher 66.

3. Der Donatistenstreit . . . . . . . . . . . . . . . 68

Gunstbeweise des Kaisers gegen die Christen in Afrika 68. [722]

Protest der Donatisten 69. Die Vorgeschichte 69. Wahl des Caecilian 70. Konstantin zur Entscheidung genötigt 71. Synode zu Rom (313) 72. Synode zu Arles (314) 74. Die Donatisten appellieren an den Kaiser 75. Entscheidung in Mailand (315) 77. Gesetze gegen die Donatisten 77. Zurückweichen der Regierung 78.

4. Der arianische Streit bis zum Tode Konstantins . . . 80

Das Vorspiel in Agypten unter Dionysios v. Alexandria 80. [734]

Vorsto $\beta$ der Sabellianer 81. Dionys von Rom hereingezogen 82. Apologie des alexandrinischen Dionys 83. Pietäts. verhältnis zu Rom 84. Das Homousios 85. Paulus von Samosata Bischof von Antiochia 85. Synode von 268 in Antiochia setzt ihn ab 87. Seine Lehre 87 . Homousios 88. Das meletianische Schisma 89. Bußvorschriften des Petrus von Alexandria 91. Opposition und Kirchengründung des Meletios 92. 
Arius wird angezeigt und verurteilt 93. Die Lukianisten für ihn 94. Seine Lehre 94. Alexanders Gegenthesen 97. Eingreifen der Lukianisten 99. Konstantin vermittelt durch Ossius 100. Synode zu Antiochia (324) 102. Generalsynode nach Nicaea (325) einberufen 103. Eröffnung 105. Das Homousios 106. Die Synode unterwirft sich 108. Die Opponenten 108. Die Kanones 109. Regelung der Osterberechnung 109. Staatliche Durchführung der Konzilsbeschlüsse 111. Schwierigkeiten in Agypten und zweite Tagung von Nicaea (327) 111. Eustathios von Antiochia abgesetzt 113. Antiochenische Kanones 115. Alexander von Alexandrien stirbt (328) 116. Athanasius gewählt 117. Meletianer gegen Athanasius 118. Arius nicht aufgenommen 119. Konstantin und Arius 119. Die „Ermordung " des Arsenius 120. Synode zu Caesarea (334) von Athanasius abgelehnt 121. Synode zu Tyrus (335) 122. Athanasius flieht nach Konstantinopel 123. Kirchweih in Jerusalem 123. Athanasius nach Trier verbannt 124. Konstantins Tod 125.

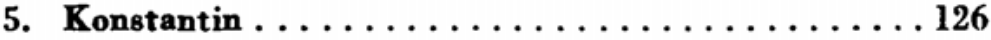

Grenzsicherung 126. Aufstand des Calocaeros 126. Cris-[780] pus 126. Dalmatius und Hannibalianus 127. Verwaltungsreform 127. Reichs- und Hofämter 128. Heerwesen 129. Steuern 130. Münzwesen 130. Rechtsreform 132. Neue Gesetze 132. Augustus und Konstantin 134. Konstantinopel gegründet 134. Kirchenbauten in der Hauptstadt und in der Provinz 136: im Abendland 138. Verfall der Tempel 139. Zukunftsdeutung des Haruspex verboten 139. Der Tempel in Hispellum 140. Konstantins Stellung zum Christentum 141. Die Schlacht am Ponte Molle bei Christen und Heiden 141. Briefliche Xußerungen Konstantins 143. Zurüickhaltung auf den Münzen 145. Konstantin als Prediger 147 und Theologe 149. Seine Bluturteile 152. Friede auf Erden 153.

6. Der Geist der konstantinischen Zeit . . . . . . . . 154

Eusebius von Caesarea 154: Chronik 155. Praeparatio und [808] Demonstratio zvangelica 157. Apologetik 158. Bibelkommentare 159. Kirchengeschichte 159. Eusebs Kuiturideal 161. Lebensbeschreibung Konstantins 161. Theophanie 162. Gregor der Wundertäter 162. Methodios von Olympos 163. Scriptores Historiae Augustae und Panegyriker 164. Arnobius 165. Laktantius 166: seine Apokalyptik 169. Optatianus Porphyrius 172.

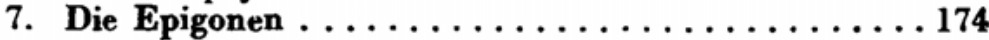

Konstantins Söhne 174. Erbteilung und Verwandten- [828] mord 175. Tod Konstantins II. 176. Konstantius 176. Rückkehr der Verbannten 178. Athanasius in Alexandria 179. Eusebius von Nikomedia wird Bischof von Konstantinopel. Neue Absetzungen 179. Pistos „Arianerbischof" in Alexandria 180. Anklagen gegen Athanasius 180. Verhandlungen mit Julius v. Rom 181. Athanasius vertrieben, Gregor in Alexandria (339) 182. Enzyklika des Athanasius 183: er geht 
nach Rom 184. Marcell von Ankyra 184. Julius schreibt an die Eusebianer 185. Antwort des Euseb 186. Römische Synode: Brief des Julius an die Orientalen 187. Marcell in Rom für rechtgläubig erklärt 190. Kirchweihsynode zu Antiochia 191. Die Bekenntnisformeln 191. Tod des Euseb von Konstantinopel. Unruhen in der Hauptstadt 193. Die „vierte antiochenische Formel“" 194. Synode von Serdika (342) 195: ihre Kanones 199; dieHuldigung für Rom 200. Protestaktion derOrientalen 201. Die abendländische Gesandtschaft in Antiochia 203. Gregor von Alexandria stirbt. Athanasius zurückberufen 203. Seine Heimkehr (346) 204. Die Formula makrostichos 205 . Synode zu Mailand. Photin von Sirmium verurteilt 205. Athanasius bricht mit Marcell 206. Synode zu Sirmium (347). Ursacius und Valens schließen sich an Rom an 207.

8. Konstantius als Alleinherrscher . . . . . . . . . 208

Aufstand des Magnentius. Vetranio 208. Schlacht bei Mur- [862] sa 209. Absetzung des Photin von Sirmiuin 210. Klagen gegen Athanasius 210. Liberius von Rom greift ein 211. Konstantius fordert Verdammung des Athanasius 212. Synode zu Mailand (355): die Oppositionsführer verbannt 213. Athanasius aus Alexandria vertrieben (356) 214: Georg eingesetzt 215. Der Caesar Gallus in Antiochia beseitigt 215. Julian an den Rhein geschickt 216. Die Einheitsformel von Sirmium (357) 217. Eudoxios von Antiochia 217 und der Neuarianismus des Aëtios und Eunomios 218. Homousios als Stichwort der Gegner 219. Die Homoiusianer in Ankyra (358) 219. Athanasius und das Homousios 220. Basilius von Ankyra siegt über Eudoxios und seinen Anhang 222. Synode zu Sirmium (358) 222. Liberius unterwirft sich 223. Das "Homoios" von Sirmium 225. Doppelsynode zu Rimini und Seleukia (359). Rimini 225. Nike 227. Seleukia 228. Abschluß in Konstantinopel 230. Synode der Acacianer 230. Der Sieg des Homoios 231. Neuer Perserkrieg 232. Julian zum Augustus ausgerufen 233. Tod des Konstantius 234.

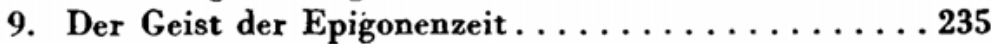

Gesetze gegen die alten Kulte 235. Konstantius in Rom 236. [889]

Kalender des Filocalus 237. Konstantinopel als neues Kulturzentrum 239. Themistios 239. Antiochia. Libanius 240. Athen und sein Studentenleben 241. Prohaeresios. Eunapios 242. Themistius und Libanius. Jamblichos 243. Christliche Literatur: Didymos der Blinde. Titus von Bostra 245. Kyrill von Jerusalem 246. Athanasius als Schriftsteller 247. Seine Erlösungslehre 248. Reden gegen die Arianer 250. Abendländer: Aurelius Victor. Nonius Marcellus 252. Aelius Donatus. Marius Victorinus 253. Chalcidius. Firmicus Maternus 256. Hilarius von Poitiers 257. Lucifer von Cagliari 260.

10. Julian . . . . . . . . . . . . . . . . . 262

Thronbesteigung 262. Jugend und Studium 263. Libanius. [916] Maxinus von Ephesus 264. Bruch mit dem Christentum 264. 
Neugestaltung des Hoflebens. Ehrung des Senats 265. Ideale Bestrebungen. Erneuerung des Stadtwesens 266. Wiederherstellung der alten Kulte 266. Gewaltsamkeiten des Volkes 267. Rückkehr der verbannten Bischöfe 268. Athanasius 268. Alexandrinische Synode (362): das antiochenische Schisma 269. Das theologische Einigungsprogramm von Alexandria 270. Spaltung in Antiochia 271. Apollinaris von Laodicea 271. Lehre von der Homousie des HI. Geistes 274. Maximus von Ephesus am Hof 275. Schärferes Auftreten gegen die Christen. Das Unterrichtsgesetz 276. Julian siedelt nach Antiochia über 278. Enttëuschungen 278. Julians neuplatonische Religion 279. Reformprogramm für das Priestertum 280. Das christliche Vorbild 281. Schikanen 282. Neubau des Jerusalemer Tempels 284. Unbeliebtheit bei den Antiochenern 285. Misopogon und Caesares 287. Der Perserfeldzug 288. Julians Tod. 290.

11. Der Kultus . . . . . . . . . . . . . . . . . . . . . . 292

Quellen der Liturgie 292. Das Kirchgebäude 293. Der [946] Hauptgottesdienst: „Katechumenenmesse“ 293. Biblische Lesungen und Perikopenordnung 294. Predigten 294. Die „Gläubigenmesse“ 295. Das Opfer 298. Landschaftliche Verschiedenheiten 299. Abendländische Liturgien. Mailand 300. Rom. Schwinden der Epiklese 301. Der Opferakt als Mysterium 301. Reichere Ausgestaltung des Gottesdienstes: Kleidung 302. Die „Einzüge“ 303 . Häufigkeit des Gottesdienstes 303. Laudes und Vesper 305. Die täglichen Gebetsstunden 306. Hymnen 307. Einfluß des Mönchtums. Nachtfeiern 307. Pilgerfahrten ins Heilige Land: der Pilger von Bordeaux 308. Aetheria 308. Bauten am Heiligen Grabe 309. Der Kult in Jerusalem: Der tägliche Gottesdienst 310. Sonntag 311. Osterzeit: das Fasten 312. Palmsonntag. Gründonnerstag 313. Karfreitag mit Kreuzesverehrung 314. Karsamstag und Osternacht: Taufe 315. Ostersonntag. Dauer der Fastenzeit 316, Fastengebete. Predigtreihen 318. Biblischo Bildreihen 319. Beschreibungen bei Âmbrosius, Prudentius, Paulinus von Nola 320. Epiphanie und Weihnachten 321 . Ausbreitung der Epiphanie im Osten 321. Das Weihnachtsfest kommt zum Osten aus Rom 322. Weihnachten und Epiphanie im Westen 323. Ausgleich der Inhalte 325. Ungelöste Probleme 326. Ursprung der Epiphanie 327 und des Weihnachtsfestes 329. Heiligenfeste 329. Petrus- und Paulustag. Petri Stuhlfeier 320. Bischofstage 331. Der syrische Kalender von Nikomedia 332. Aposteltage des Ostens 334. Reliquienkult 335 . 
XXXVI

\section{Die Zeit der Kirchenväter}

1. Jovian, Valentinian und Valens $\ldots \ldots \ldots \ldots \ldots \ldots \ldots \quad 1$

Wiederaufleben der kirchlichen Gegensätze 1. Synoden in [993]

Alexandria 2 und in Antiochia 3. Kirchenpolitik der neuen

Kaiser 4. Verbannungen unter Valens 5. Die Romreise des

Eustathius 6. Neue theologische Führer 8. Das Einigungswerk des Basilius: Versuch mit Athanasius 10. Die Mission des Sabinus 13. Basilius schidkt Dorotheus nach Rom 15. Die beiden Reisen des Dorotheus und des Sanctissimus 17. Basilius' Tod 20. Gotenkrieg 21. Valens fällt 23.

2. Theodosius I. und das Ende des arianischen Streites .... 24

Friede mit den Goten 25. Theodosius einigt die östliche [1016]

Kirche 26. Meletius 27. Gregor v. Nazianz in Konstantinopel 28. Der Anschlag des Philosophen Maximus 30. Das 2. ökumenische Konzil 32. Seine Kanones 34 und seine Trinitätslehre 36 .

3. Der Westen unter Valentinian I. und Gratian ........ 40

Die Luciferianer 40. Damasus und Ursinus 41. Die „illy- [1032]. rischen" Homöer 42. Damasus befestigt seine Stellung 44. Roms Vorrechte 46. Ambrosius von Mailand 47. Gratian und der Kirchenfrieden 49. Ambrosius bekämpft den illyrischen Arianismus 50. Synode in Aquileia 52, ihr Eingreifen in die Fragen der östlichen Kirche 54 endet mit einer Niederlage 56.

4. Ambrosius und Theodosius .................. 59

Festigung der Staatskirche 60. Der Tyrann Maximus 61. [1051]

Priscillianus 62. Gegner des Priscillianismus 64. Blutige Unterdrüdkung durch Maximus 66. Der Streit um den Altar der Victoria 67. Ambrosius formuliert die Pflichten des christlichen Herrschers 68. Konflikt mit der Kaiserin-Mutter Justina 69 und Valentinian II. 72. Theodosius wird Alleinherrscher 75, sein Verhalten gegen das Heidentum im Westen 76 und im Osten 77. Geistlicher Einfluß des Ambrosius 78. Sacrum Imperium 80. Der Aufstand des Eugenius 83. Ambrosius nimmt gegen ihn Partei 84. Kaiser und Bischof 86. 
5. Volksfrömmigkeit im vierten Jahrhundert ......... 89

Veränderte Grundbedingungen in der Reichskirche 89. My-
steriensehnsucht 90 . Erwadhsenentaufe 91 . Christenlehre nach Kyrill von Jerusalem 93. Gnade und Wille 94. Glaube 95. Gott 95, Christus 96. Gerichtserwartung 97. Hl. Geist 98, Kirche 98. Sakramentsmystik 100. Die Großstadtgemeinde des Johannes Chrysostomus 102. Biblizismus 104. Aberglaube und jüdische Riten 105. Der Christ und die Zeitnöte 107. Vollkommenheit und Weltchristentum 112. Der Märtyrer als Vorbild und Schutzpatron 114.

6. Das Mönchtum

V or s t u f e n (116-124). Asketisches bei Jesus und Pau- [1108] lus 116. Besitz und Ehe im Urchristentum 118. Abwertung des Leibes 120. Asket und Pneumatiker 121. In den Sekten wird Ehelosigkeit für alle verlangt 122. Aufstieg durch Askese zur Gnosis bei den Alexandrinern 123. Gibt es außerchristliche Vorbilder für das Mönchtum? 124.

Anachorese und K losterwesen (125-141). Antonius 125. Die Antoniusvita des Athanasius 127. Dämonenglaube 128. Agyptische Einsiedler 129. Die „Apophthegmata Patrum " 131. Altestes Klosterwesen: Pachomius und seine Regel 132. Die Klosterordnung 135. Gottesdienste 136. Ausbreitung 139.

Mön c h sf rö m m i g k e i t (141-154). Die Quellen 141. Dämonenfurcht 142. Stellung zum Dogma 143 und zur Bibel 144. Gebetsexerzitium 145. Sündenbewußtsein 146. Visionen und Ekstase 147. Demutsideal 148. Geltung von Kirche und Sakrament 149. Der wundertätige Mönch 151. Verbreitungdes Mönch tums (154-174). Palästina 155. Syrien 157: Afrahat, Audianer 157, Messalianer 159. Asketische Spitzenleistungen: Symeon Stylites 161. Die Akoimeten 163. Kleinasien: Eustathius v. Sebaste 164, Basilius d. Gr. 165. Konstantinopel 166. Das Abendland: der hl. Martin 167. Die Küsten 169, Spanien, Afrika 170, Italien, Rom 171. Gegner des Mönchtums 171, Jovinian 172. Hieronymus 173.

Mönchstheoretiker (174-193). Symeon v. Mesopotamien 174. Der Liber Graduum 181. Euagrius Ponticus 184. Basilius d. Gr. 189.

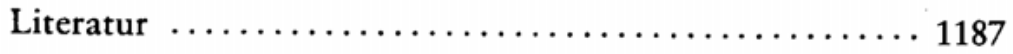

Register ............................... 1194

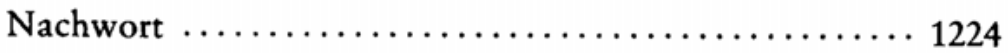


